Published in final edited form as:

Bio Protoc. 2015 December 20; 5(24): . doi:10.21769/BioProtoc.1682.

\title{
$\left[{ }^{14} \mathrm{C}\right]$ Linoleic Acid Uptake and Fractionation Assay in Vibrio cholerae
}

\author{
Sarah C. Plecha and Jeffrey H. Withey ${ }^{*}$ \\ Department of Immunology and Microbiology, Wayne State University School of Medicine, \\ Michigan, USA
}

\section{Abstract}

The gram-negative curved bacillus Vibrio cholerae ( $V$. cholerae) causes the severe diarrheal illness cholera. The work presented here is to assess whether unsaturated fatty acids (UFAs), such as linoleic acid, have the potential to directly affect proteins involved in DNA binding because they are able to enter the cell. In this protocol, we show how to measure linoleic acid entering $V$. cholerae when added exogenously and determine whether it is able to enter the cytoplasm. This protocol will quantify how much linoleic acid is able to enter the cell and then identify the amount of linoleic acid that stays in the membrane or ultimately enters the cytoplasm.

\section{Materials and Reagents}

1. Scintillation vials (Thermo Fisher Scientific, catalog number: 03-337-20)

2. Autoclaved $1.7 \mathrm{ml}$ microcentrifuge tubes (BioExpress, catalog number: C-3262-1)

3. Test Tubes (Thermo Fisher Scientific, catalog number: 14-955E)

4. $15 \mathrm{ml}$ conical screw cap tubes (BioExpress, catalog number: C-3394-2)

5. Vibrio cholerae classical biotype strain $\mathrm{O} 395$

6. ${ }^{14} \mathrm{C}$ linoleic acid (PerkinElmer, catalog number: NEC501050UC)

7. Scintillation cocktail (Thermo Fisher Scientific, catalog number: SX18-4)

8. Tryptone (Thermo Fisher Scientific, catalog number: B211705)

9. Yeast Extract (Thermo Fisher Scientific, catalog number: B288620)

10. Sodium chloride $(\mathrm{NaCl})$ (Thermo Fisher Scientific, catalog number: BP358-212)

11. Potassium chloride $(\mathrm{KCl})$ (Thermo Fisher Scientific, catalog number: BP366-500)

12. Sodium phosphate $\left(\mathrm{Na}_{2} \mathrm{HPO}_{4}\right)$ (Thermo Fisher Scientific, catalog number: BP332-500)

\footnotetext{
*For correspondence: jwithey@ wayne.edu.
} 
13. Potassium phosphate $\left(\mathrm{KH}_{2} \mathrm{PO}_{4}\right)$ (Thermo Fisher Scientific, catalog number: BP362-500)

14. Tris-Base (Thermo Fisher Scientific, catalog number: BP152-500)

15. $95 \%$ ethanol (Decon Labs, catalog number: 2805HC)

16. Dry ice

17. LB-Lennox ( $\mathrm{pH}$ 6.5) (see Recipes)

18. 10x PBS (see Recipes)

19. $20 \mathrm{mM}$ Tris-Base ( $\mathrm{pH} 8.5$ ) (see Recipes)

20. $500 \mathrm{mM} \mathrm{NaCl}$ (see Recipes)

\section{Equipment}

1. Shaker-capable of shaking at $200 \mathrm{rpm}$ at $37{ }^{\circ} \mathrm{C}$ (VWR International, New Brunswick Scientific, model: Excella E25)

2. Water bath shaker-capable of shaking at $30^{\circ} \mathrm{C}$ at $200 \mathrm{rpm}$ (VWR International, New Brunswick Scientific, model: Classic C76)

3. LS6000IC liquid scintillation counting system (Beckman Coulter)

4. Timer

5. Autoclave

6. Biomate $3 \mathrm{~S}$ Spectrophotometer-capable of reading at $\mathrm{OD}_{600}$ (Thermo Fisher Scientific)

7. Semimicro Cuvettes (Thermo Fisher Scientific, catalog number: 14-955-127)

8. Table top Centrifuge-capable of spinning at $15,000 \mathrm{rpm}$ at $4{ }^{\circ} \mathrm{C}$ (Eppendorf, catalog number: 5424)

9. Micropipettes $(1,000 \mu \mathrm{l}, 200 \mu \mathrm{l}, 20 \mu \mathrm{l})$

10. $250 \mathrm{ml}$ Erlenmeyer flask

\section{Procedure}

A. $\quad\left[{ }^{14} \mathrm{C}\right]$ linoleic acid uptake

1. Use one colony of $V$. cholerae classical biotype strain $\mathrm{O} 395$ to start an overnight culture in a test tube containing $5 \mathrm{ml}$ standard LB at $37^{\circ} \mathrm{C}$ and 200 rpm shaking.

2. After overnight growth, subculture the bacteria $250 \mu \mathrm{l}$ in $10 \mathrm{ml} \mathrm{LB} \mathrm{pH}$ 6.5 (1:40 ratio) in an Erlenmeyer flask, and grow for $2 \mathrm{~h}$ in a water bath shaker at $30{ }^{\circ} \mathrm{C}$.

3. At $2 \mathrm{~h}$, record the $\mathrm{OD}_{600}$ of the culture. Expect an $\mathrm{OD}_{600}$ of between 0.2 and 0.3 . 
4. Transfer the culture to a $15 \mathrm{ml}$ falcon tube and add $0.1 \mu \mathrm{Ci}(1 \mu \mathrm{l})$

of ${ }^{14} \mathrm{C}$-radiolabeled linoleic acid for each milliliter of the subculture (final concentration of about $3.2 \mathrm{mM}$ linoleic acid). This tube can stay on the bench top for the duration of the experiment or, if desired, put at $37^{\circ} \mathrm{C}$ without agitation between aliquots.

5. Upon addition of the radiolabeled linoleic acid, extract $1 \mathrm{ml}$ of the culture and immediately centrifuge in a $1.5 \mathrm{ml}$ microcentrifuge tube at $15,000 \mathrm{rpm}$ for $3 \mathrm{~min}$ at room temperature. This is $\mathrm{t}=0$. In order to compare the counts per minute $(\mathrm{CPM})$ of ${ }^{14} \mathrm{C}$ in the supernatant and the cell pellet, transfer the supernatant in a $1.5 \mathrm{ml}$ tube and wash the cell pellet 3 times with $1 \mathrm{ml}$ of $1 \mathrm{x}$ PBS and centrifuge each for $3 \mathrm{~min}$.

6. Resuspend the cell pellet in $100 \mu \mathrm{l}$ of $1 \mathrm{x}$ PBS and add to $5 \mathrm{ml}$ of scintillation cocktail per scintillation vial. In order to compare the amount of ${ }^{14} \mathrm{C}$-radiolabeled linoleic acid not taken up by $V$. cholerae, add $100 \mu \mathrm{l}$ of the supernatant fraction to another vial with $5 \mathrm{ml}$ scintillation cocktail.

7. The same procedure can be repeated for other aliquots of the subculture at times 5, 15, and $30 \mathrm{~min}$ or whatever time points are desired. All scintillation vials can be stored at room temperature and read together after the last time point.

8. After uptake, counts per minute are measured for each time point using a scintillation counting system.

9. Data are then analyzed using the cpm determined from the cell pellet fraction and an equation of best fit determined. To determine how much ${ }^{14} \mathrm{C}$-radiolabeled linoleic acid is not taken up as a check of accuracy, use cpm determined from the supernatant fraction and multiply by 10 as only $100 \mu \mathrm{l}$ of the $1 \mathrm{ml}$ was used. The amount of ${ }^{14} \mathrm{C}$ radiolabeled linoleic acid in the cell pellet is graphed below for each time point:

B. Fractionation of $V$. cholerae to determine localization of $\left[{ }^{14} \mathrm{C}\right]$ linoleic acid

1. After overnight growth at $37{ }^{\circ} \mathrm{C}$ as described in step A1, subculture $V$. cholerae $\mathrm{O} 395$ classical biotype $250 \mu \mathrm{l}$ in $10 \mathrm{ml} \mathrm{LB}$ (pH 6.5) (1:40 ratio) and grow in a water bath shaker at $30^{\circ} \mathrm{C}$ for $2 \mathrm{~h}$.

2. At $2 \mathrm{~h}$, add $0.1 \mu \mathrm{Ci}$ of ${ }^{14} \mathrm{C}$-radiolabeled linoleic acid to $1 \mathrm{ml}$ of the subculture and incubate at room temperature for $1 \mathrm{~h}$ without agitation. This time is chosen to ensure the bacteria are still in log-phase growth.

3. Harvest the bacteria by centrifugation $(15,000 \mathrm{rpm})$ at room temperature for $3 \mathrm{~min}$ and wash the pellet three times with $1 \mathrm{ml} 1 \mathrm{x}$ PBS at 15,000 rpm for 3 min each time.

4. Resuspend the bacteria in a $500 \mu$ solution of $20 \mathrm{mM}$ Tris-Base (pH 8.5 ) and $500 \mathrm{mM} \mathrm{NaCl}$. Freeze the suspension in an ethanol (at least 
$95 \%$ ) and dry ice bath for 2 minutes ensuring the tube is fully submerged, and then put at $37{ }^{\circ} \mathrm{C}$ until thawed. Repeat this freeze-thaw process for a total of three freeze-thaw cycles to ensure complete fractionation.

5. Fractionate the bacteria by centrifugation for $10 \mathrm{~min}$ at $15,000 \times g$ at $4{ }^{\circ} \mathrm{C}$ to separate the membrane and cytoplasm. The cytoplasm is taken as the supernatant and the pellet (cell envelope fraction) is washed 3 times in $500 \mu \mathrm{l}$ of $1 \mathrm{x}$ PBS by centrifuging for $3 \mathrm{~min}$ at $15,000 \times \mathrm{g}$. Expect a very small pellet at the bottom of the tube. The amount of ${ }^{14} \mathrm{C}$ linoleic acid in each fraction is determined by adding the entire fraction to $5 \mathrm{ml}$ scintillation cocktail, followed by measurement of CPM in a scintillation counter.

6. Data are then analyzed as percent ${ }^{14} \mathrm{C}$-linoleic acid in each fraction. A representative graph is shown below:

\section{Recipes}

1. LB-Lennox (500 ml) $(\mathrm{pH} 6.5)$

5 g tryptone

$2.5 \mathrm{~g} \mathrm{NaCl}$

2.5 g yeast extract

Add about $400 \mathrm{ml}$ of water to dissolve and mix the components

$\mathrm{pH}$ to 6.5 with $\mathrm{HCl}$ and bring up to $500 \mathrm{ml}$ with water

Autoclave before use

2. $10 x$ PBS $(1 \mathrm{~L})$

$80 \mathrm{~g} \mathrm{NaCl}$

$2 \mathrm{~g} \mathrm{KCl}$

$14.4 \mathrm{~g} \mathrm{Na}_{2} \mathrm{HPO}_{4}$

$2.4 \mathrm{~g} \mathrm{KH}_{2} \mathrm{PO}_{4}$

To use, dilute 1:10 (such as $10 \mathrm{ml}$ brought up to $100 \mathrm{ml}$ with autoclaved water)

3. $20 \mathrm{mM}$ Tris-base $(\mathrm{pH} 8.5)(100 \mathrm{ml})$

0.24 g Tris-base

$\mathrm{pH}$ to 8.5 with $\mathrm{HCl}$ and bring up to $100 \mathrm{ml}$ with water

Autoclave before use

4. $\quad 500 \mathrm{mM} \mathrm{NaCl}(100 \mathrm{ml})$

$2.92 \mathrm{~g} \mathrm{NaCl}$ 


\section{Acknowledgments}

This work was supported by P. H. S. grants K22AI071011 and R56AI093622 and Bill and Melinda Gates Foundation grant OPP1068124 (to J. H. W.).

This work is modified from previous work done in our laboratory (Thomson and Withey, 2014).

\section{References}

1. Plecha SC, Withey JH. Mechanism for inhibition of Vibrio cholerae ToxT activity by the unsaturated fatty acid components of bile. J Bacteriol. 2015; 197(10):1716-1725. [PubMed: 25733618]

2. Thomson JJ, Withey JH. Bicarbonate increases binding affinity of Vibrio cholerae ToxT to virulence gene promoters. J Bacteriol. 2014; 196(22):3872-3880. [PubMed: 25182489] 


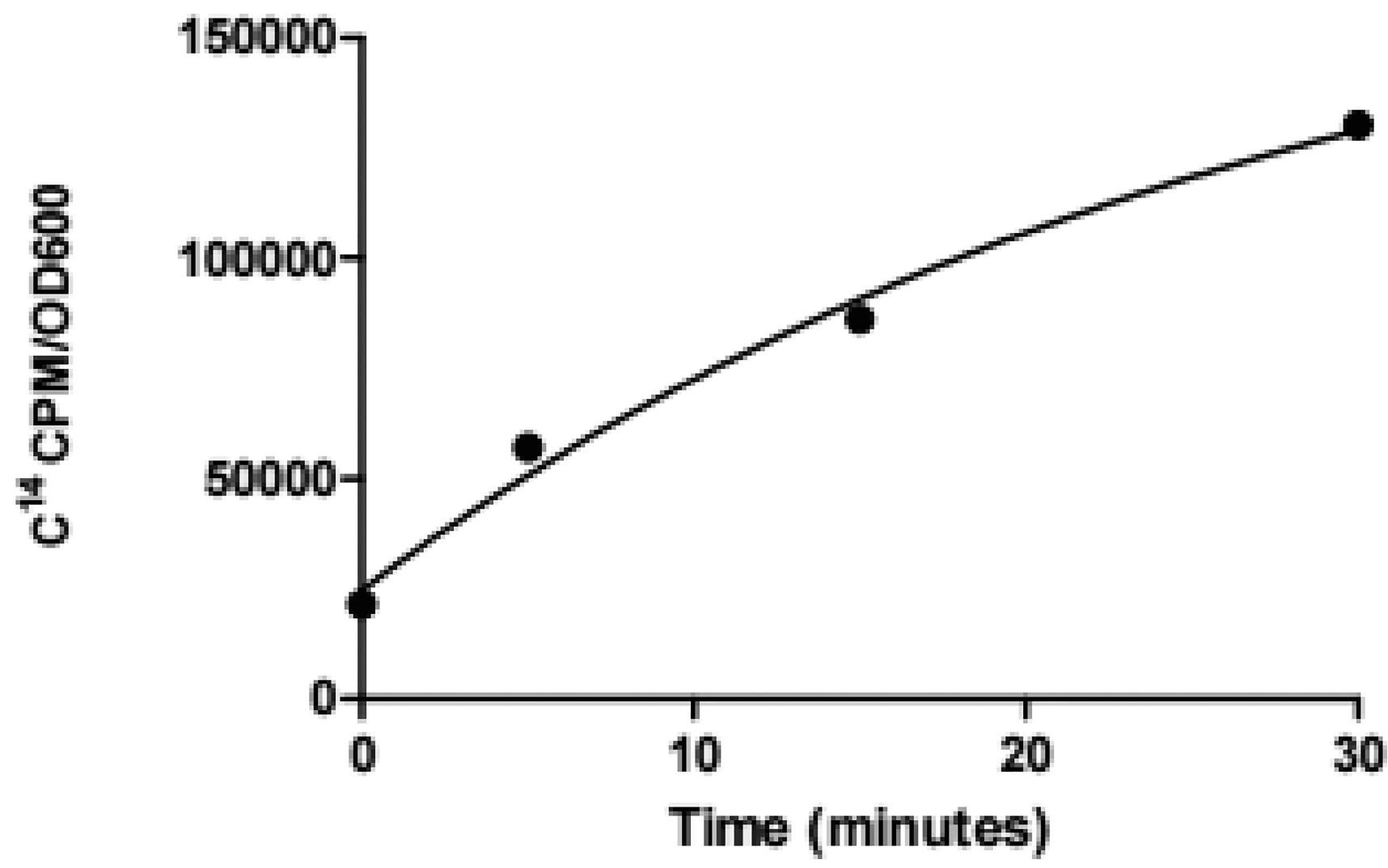

Figure $1 .{ }^{14} \mathrm{C}$-radiolabeled linoleic acid uptake by V. cholerae

The equation of best fit is $y=24622+156786^{*}\left(1-e^{-0.036 x}\right)$ with an $R^{2}$ value of 0.989 . 


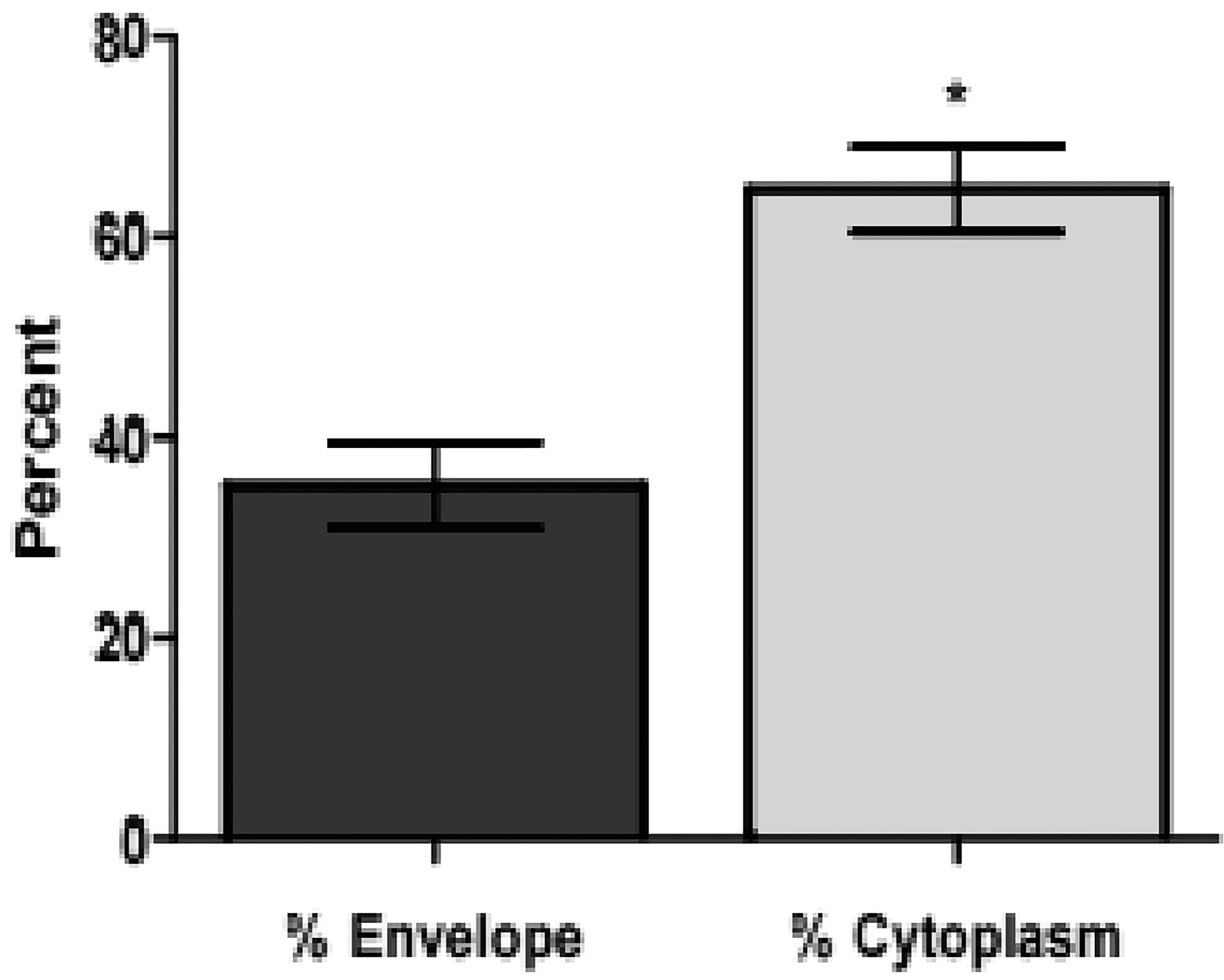

Figure 2. Percentages of ${ }^{14} \mathrm{C}$-radiolabeled linoleic acid in cytoplasm and envelope fractions 